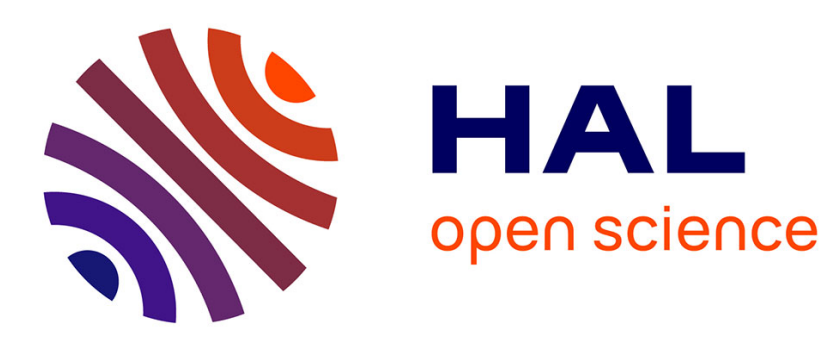

\title{
New perspectives on language development and the innateness of grammatical knowledge
}

Christophe Parisse

\section{To cite this version:}

Christophe Parisse. New perspectives on language development and the innateness of grammatical knowledge. Language Sciences, 2005, 27, pp.383-401. 10.1016/j.langsci.2004.09.015 . halshs00090997

\section{HAL Id: halshs-00090997 https://shs.hal.science/halshs-00090997}

Submitted on 5 Sep 2006

HAL is a multi-disciplinary open access archive for the deposit and dissemination of scientific research documents, whether they are published or not. The documents may come from teaching and research institutions in France or abroad, or from public or private research centers.
L'archive ouverte pluridisciplinaire HAL, est destinée au dépôt et à la diffusion de documents scientifiques de niveau recherche, publiés ou non, émanant des établissements d'enseignement et de recherche français ou étrangers, des laboratoires publics ou privés. 
This is the penultimate version of an article to appear in Language Sciences (2004)

Title: New perspectives on language development and innateness of grammatical knowledge

Author: Christophe PARISSE

Affiliation: Institut National de la Santé et de la Recherche Médicale (INSERM), Paris, France

Abstract : Chomsky $(1965,1986)$ presents a series of arguments for an innate syntactic component of the language faculty. Do the arguments proposed at that time still stand, or have they been overridden by newer proposals? The current paper emphasizes three research directions among the most recent advances in cognitive science. These directions lead to alternate proposals to the generative linguistic theory of language development. First, the 'item-based' theory of language development, which stresses that development of language knowledge goes from specific to general and is compatible with developing research in cognitive linguistics. Second, the apparent uniformity of adult linguistic competence, which is a fundamental tenet of generative linguistics theory, may be the product of literate cultures but not of invariants of the brain, as attested by the fundamental differences found between spoken and written language. Third, artificial neural networks provide evidence against the necessity to call on algebraic rules to explain language performance and this, in turn, argues in favor of the emergence approach and of the dynamic systems approach to language development. All this calls for a renewal of language development theories and for a separation between statistical, non-algebraic, non-conscious, item-based, and usage-based structures and processes dedicated to spoken language (and to automatized written language processes), and principle-and-rule-governed, algebraic structures and processes dedicated to conscious written or formal spoken language.

Keywords: language development, syntax, innateness, spoken and written language 
Title: New perspectives on language development and innateness of grammatical knowledge

\section{Introduction}

Chomsky (1965) presented a series of arguments that called for an innate syntactic component of the language faculty, which is necessary for language acquisition by children and at the core of adult language competence. The core of this faculty is usually called 'universal grammar' (UG). Chomsky's (1965) arguments have been reproduced and developed by Chomsky himself as well as by other authors throughout the years (see in particular Chomsky, 1986; Hauser, Chomsky, \& Fitch, 2002; Jackendoff, 2002; Pinker, 1990; Pinker, 1994). These ideas have also had a large impact on many research fields, and the theory of UG is the most well-known theory of language acquisition outside the field of language acquisition research. However, the theory has never met with the full agreement of the research community and many criticisms have been leveled against it ever since it was developed (see for example Sampson, 1997).

How does it stand today? Is the opposition to UG still justified? Are there recent developments in linguistic theory, language acquisition theory, or in the cognitive sciences that could provide a true alternative to UG? It seems that today proposals that could lead to a redefinition of what language is and what language acquisition is do exist. This, however, implies looking at more than one research direction in linguistics and the cognitive sciences.

I will begin by presenting the logical arguments that are used to validate the UG theory of language acquisition. Then I will present three research directions that, each in its own specific way, go counter to these logical arguments. Finally, I will conclude with a discussion about the consequences that these research directions can have on linguistic approaches in language acquisition.

Two claims are fundamental to the UG theory of language acquisition:

1. Language is structured and this structure is not the most simple of all the possible structures that could be used to describe language. For example, a sentence can contain a clause that itself contains a clause, and so on. Such languages are called recursive languages and are definitely not the most simple of languages. Markov models, for example, which are very widely used in computer pattern recognition and automatic language processing, cannot describe such a class of languages. 
2. How can a child choose, out of all possible language grammars, which type corresponds to human language grammar, especially when the correct grammar is not the simplest one available? This is the famous argument about the poverty of input. Given the complexity of the problem faced by children, positive data alone is not sufficient to choose the correct grammar (Gold, 1967) - positive data being examples of well-formed sentences. It is also necessary to have negative data, which means that children have to be explicitly corrected when they produce ungrammatical utterances. The question of the existence of negative data in children's input thus became a focus point in research and although some negative data was found in children's input (Sokolov \& Snow, 1994), it appears that children do not use negative evidence per se (Marcus, 1993). Moreover, it is not certain that the very complex structure of human languages could be discovered even with some negative evidence or fine-tuning (Wexler, 1982). Finally, Chomsky (1967) argued that spoken language is full of false starts, incomplete sentences, and other deviations from ideal competence which makes the task children face even more difficult. So it is impossible for children to discover the correct grammar of their own language without having innate grammatical information that strongly reduces the set of possible natural language grammars.

The two claims above have two important correlates:

3. Human knowledge about grammar can be characterized in two different ways. First, competence, which is a description of the ideal speaker-hearer's intrinsic knowledge of grammar. Competence allows someone to know the exact set of all possible correct sentences in a language. Second, performance, which corresponds to the processes that implement competence in the human brain. Performance is hampered by physiological limitations such as memory, time. This explains the difference between the idealized set of possible sentences and the actual speech produced. Although ultimately a theory should be able to explain both competence and performance, it is competence which was the first goal of generative linguistics.

4. It is possible to find out the fundamentals and characteristics of the adult linguistic system by using the intuitive knowledge that native adult speakers have of their own language (as this intuitive knowledge comes from the faculty of language). 
Most of the arguments above were developed during the years 1964-1980. Subsequent developments of generative linguistic theories by Chomsky himself (Chomsky, 1981; Chomsky, 1995) or other researchers with a similar approach to linguistics, have not modified the validity of these arguments - for example Jackendoff (2002), who draws most of Chomsky's citations about UG from Chomsky (1965). Another indication is that the presentation of the acquisition of language in Chomsky (1986) follows the presentation above, although this book is based on the principle and parameters theory and contains an interesting reformulation using the notions of I-language and E-language. Chomsky's (1995) book on the minimalist program does nothing to change this. In this book, Chomsky still uses the term UG to describe the initial linguistic knowledge (see p. 166). Hauser et al. (2002) shows a shift in language use. They say 'Such constraints have historically been termed "innate dispositions," with those underlying language referred to as "universal grammar." Although these particular terms have been forcibly rejected by many researchers $[\ldots]$, the existence of some such constraints cannot be seriously doubted' (p. 1577). They replace the notion of UG by a more general notion of 'faculty of language: narrow sense', which includes the capacity of recursion (the existence of which is implied by the characteristics of UG). This shift is also demonstrated in Chomsky (2000), where reference is made to 'the initial state of the language faculty' (see p.4) but not to UG. However, the change in vocabulary does not change the arguments developed above. In Hauser et al. (2002), arguments 1 and 2 above are reproduced: argument 1 is extended to the notion of recursion and potential infinity (see $\mathrm{p}$. 1571 ) ; argument 2 is not changed: reference to Gold (1967) is made and the existence of a set of constraints that creates a bias towards certain types of grammar is claimed (see p. 1577). The reason is that Chomsky's most recent linguistic theories correspond to the same category of grammars, so any previous mathematical demonstration still holds.

As the term UG is still the most frequently used term to describe the notion of innate syntactic knowledge, I have chosen to use it in this paper. Some authors prefer other terms, such as 'language instinct' (Pinker, 1994). My use of a term that Chomsky himself does not use anymore is a reminder that the arguments presented, although often associated with Chomsky's work, apply to other mentalist generative theories, such as for example Pinker's or Jackendoff's. It is also worth mentioning that generative linguistics is not dependent on the principle of UG. For this reason, the criticisms below do not apply to non-mentalist generative approaches to language. However, at least in language acquisition research, which has a strong mentalist stance, UG is most often closely associated with generative theories of 
language. This is true for example of works in language acquisition by Atkinson (1992), Clahsen (1990), Hyams (1986), Radford (1990), Wexler (1999), which are based on principles and parameters theory, or of the works of Pinker, which are not based directly on a specific version of Chomsky's theories (Pinker's most technical work uses Lexico-Functional Grammar).

Chomsky's research goal is to find out what linguistic knowledge is available to all human beings at birth. This goal is shared by a large part of the specialists in language acquisition, but another equally large part is still reluctant to adopt Chomsky's ideas about what language and language acquisition are. Many people have tried to counter these ideas and to construct and test other theories more in keeping with their views of what language is, but there is still no widely accepted alternative to the theory of innate syntactic knowledge in language acquisition research. This may be explained by the solidity of the arguments for the existence of UG (as presented above) and by the very complexity of language and language development. The following three proposals are not the sole proposals that have been developed since then, nor are they necessarily the most developed ones. What is more important here is that they complement each other. They do not all criticize the same points, and when they converge on the same criticism, their reasoning is based on different arguments. Their complementarity also comes from the fact that they represent different domains of linguistics and psycholinguistics. This multidimensionality contributes to the creation of an alternative to the UG view of language and language acquisition.

\section{Item-based learning}

In generative theories of language, children have an innate knowledge of grammar and language, which means that they have the same intrinsic linguistic knowledge as adults. There is a continuity between the systems of the child and of the adult (Tomasello, 2000a). However, it is still necessary for children to make the link between the elements of UG and the actual elements of their mother tongue. Several answers to this problem have been proposed, such as 'semantic bootstrapping' by Pinker (1987), or 'cerebral maturation' by Wexler (1999).

The notion of 'item-based learning' runs contrary to the generative theory principle of continuity between child and adult grammatical knowledge. Tomasello (1992), looking at the production of young children aged one to three, discovered that the children do not have syntactic knowledge about the verb category from their youngest age on, despite the fact that 
they produce numerous forms that are verbs. What Tomasello noticed is that children begin with using specific item-centered forms, whereas if children had intrinsic knowledge of the verb category, they should be able to extend the knowledge they display with one verb to other verbs:

'For example, at 23 months of age the verb "cut" was used in only one simple construction type (Cut _ $)$ whereas the similar verb "draw" was used in many different construction types, some with much complexity (e.g. I draw on the man, Draw it by Santa Claus).' ... 'Some verbs were used with lexically expressed subjects whereas others at the same time were not, even though they were used in comparable construction types and in comparable pragmatic contexts (e.g. T produced subjects for "take" and "get" but not for "put").' (Tomasello, 2000a, p. 213).

The child's knowledge seemed organized around a few verbs, for which she knew only specific uses. However, she was able to produce a large variety of complements for some constructions. For example, with the construction 'Cut _,', '_' acted as a placeholder for a large number of nouns and nouns phrases. Children will not reliably display the capacity to generalize the use of a verb to another verb easily before age three (Tomasello, 2000a). This change from lexicalized knowledge to syntactic knowledge does not happen at the same age for all categories. For example, it will happen at age two for the noun category, but not before age three or four for the verb category.

Other researchers (Lieven, Pine, \& Baldwin, 1997; Pine \& Lieven, 1997; Pine \& Martindale, 1996; Rowland \& Pine, 2000) confirmed these results and went further in proposing that item-based knowledge is not specific to verbs but also applies to other categories such as, for example, pronoun and noun. This is why the principle of verb-island items (Tomasello, 1992) has been extended to the more general principle of item-based constructions. Tomasello (2000a; 2000b; 2002; 2003) tries to build a theory of language development that takes item-based learning into account. He suggests that the existence of item-based constructions contradicts the idea of a continuity between child and adult grammatical knowledge. On the contrary, generative theories of language acquisition offer no mechanism to switch from one system to another and they even claim that using different grammatical knowledge at different levels of development is not a parsimonious principle. This was indeed one of the major criticisms of the pivot-grammar theory of language acquisition (Braine, 1976), which described grammatical knowledge of two-year-olds with a simplified grammar. Tomasello proposes a new constructivist theory of language 
development, where linguistic syntactic competence develops gradually up to full adult competence. There are four main arguments that make the existence of such development of syntax possible:

1. Adult competence may be very different from what is hypothesized through the generative approach. Instead of the abstract mathematical principles of the generative theory, Tomasello proposes a new paradigm that he calls 'CognitiveFunctional Linguistics' (Tomasello, 2000a, p. 236). This refers to a large body of works by numerous authors (Croft, 2000; Croft, 2001; Givon, 1995; Goldberg, 1995; Langacker, 1987; Langacker, 2000; Van Valin \& LaPolla, 1997). This linguistic approach is not syntax-centered but rather semanticcentered, which is more in keeping with what young children actually do. Furthermore, one of the principles of cognitive linguistics is that linguistic performance is usage-based (Langacker, 2000), which matches the fact that children's production is item-centered. This principle is also used in some applications in computer linguistics (e.g. Gillis, Daelemans, \& Durieux, 2000).

2. Children have the surprising ability to understand the intentions of their linguistic partners, which allows them to learn by imitation (Bruner, 1985; Dunham, Dunham, \& Curwin, 1993; Tomasello, 1995; Tomasello \& Kruger, 1992). The ability to identify the functions of their partners' actions also allows them to attribute functions to linguistic input.

3. Children can draw analogies between two structures, even though they are very different one from another. This ability allows them to extend what they have learned with one specific item to other items that share the same grammatical features. This will later be extended to general syntactic categories or constructions, such as 'subject-predicate' (see Tomasello, 2000a, p. 242).

4. Observation of children's language production (Tomasello, 1992) shows that they combine several item-centered structures into a single more complex structure. This proves that children are not limited to using the structures they have heard before.

Tomasello's proposals may appear as relevant only to the 'language faculty: broad sense' (as described in Hauser et al., 2002). This is the case for the capacity of understanding the intentions of others, which is clearly not a capacity that is specific to language. However, this is not true of points 3 and 4, which describe proposals that allow the building of language specific structures and the construction of syntactic knowledge. This is also the case in 
Tomasello's most recent book about language acquisition, (Tomasello, 2003), which includes such chapters as: 'abstract syntactic constructions', 'nominal and clausal constructions', and 'complex constructions and discourse'. All these constructions are part of the 'language faculty: narrow sense' (see Hauser et al., 2002).

An advantage of the item-centered theory of language acquisition is that it can be tested using real data, at least in its initial phase (for a first step in this direction, see Lieven, Behrens, Speares, \& Tomasello, 2003). This requires gathering large corpora with, if possible, a dense acquisition of data (every day or every week), which is possible today, especially by taking advantage of international data sharing communities such as CHILDES (MacWhinney, 2000a; MacWhinney \& Snow, 1985). It is also necessary to get more into the details of the procedures followed by children as they create linguistic combinations, especially in the case of children older than three, so as to be able to simulate these combinations on a computer. Finally, even with such a research project completely finalized, the steps from the linguistic system of a five-year-old to that of a literate adult would still remain to be explained. The explanation may be provided in part by looking at the nature of the adult linguistic system and of the system of written language.

The adult linguistic system

The concept of the adult linguistic system as presented by Chomsky is criticized by Tomasello and other proponents of the cognitive grammar approach. They claim that a complete grammatical theory should merge syntactic abilities seamlessly into cognition, and not consider them as an autonomous sub-system. This option explains why cognitive structures are fundamental to cognitive linguistics. Another proposition of generative linguistics criticized by cognitive linguists is the claim that adult grammatical system (competence) is fixed. This goes against the findings of specialists in diachronic linguistics such as Bybee (1993) or Hopper (1993). Hopper (1998) goes further and presents a grammatical system called 'Emergent Grammar', where all grammatical features are created at the very moment they are used. Such a system does not have a fixed point, which means that there cannot be any type of common adult knowledge.

These arguments coming from theoretical linguistic research are not the only ones leveled against Chomsky's generative linguistic approach. For more than twenty years now, an important body of work (Halliday, 1985; Harris, 1990; Hopper, 1998; Linell, 1982; Miller \& Weinert, 1998; Olson, 1996; Ong, 1982) has criticized the dangerous confusion between spoken and written language which can be found not only in the generative approach but also 
in many other linguistic approaches. Avoiding this confusion leads to rethinking the underlying theoretical choices of numerous linguistic works, and, especially, those that are rooted in generative linguistics. The main idea behind this criticism is that linguistic research was developed with written material, whose intrinsic properties strongly constrain the results that can be obtained, and that it was erroneously concluded that these results apply to spoken as well as to written language. This does not mean that no study has ever been done on spoken languages and spoken language -in Chomsyian linguistics as well as in other types of linguistics- or that these studies have had no impact whatsoever on existing theories (see for example Van Valin \& LaPolla, 1997), but that the basic principles of linguistic theory were created with properties of writing in mind, although maybe not knowingly. Thus, when spoken material was analysed, it was most of the time through the looking-glass of 'writinginspired' theories (see Miller \& Weinert, 1998, p. 378, p. 383).

Looking at the development of the linguistic sciences, one can see that the study of languages, their lexicon and their grammar, appeared after the development of written systems (Auroux, 1994). In fact, the analysis of languages has developed progressively during the last three millennia, in parallel with the development of the written forms of languages. This has resulted in the widely spread impression that written material is an adequate representation of spoken language (Harris, 1990; Linell, 1982; Olson, 1996). This affirmation is of course an exaggeration as many linguists who are aware of the imperfections and limits of phonetic transcriptions would not agree with this, but in most linguistic works written language is considered as a valid representation of spoken language. Furthermore, spoken language is often considered as a degraded version of language, due to the existence of psychological limits of the human brain - e.g. Chomsky's notion of performance. Written language does not have these limits or to a smaller amount and this suggests that the difference between spoken and written language may have provided the model for the notion of performance and competence. As a consequence, written language would be the true model of linguistic competence. This interpretation of linguistic research may sound extreme and an overstatement of the difference between spoken and written language. Many linguists agree that written language is not a copy of real language. Nonetheless, even recent theoretical and applied research does not take this difference into account (see Miller, 1999; Miller \& Weinert, 1998, pp. 373-425). As an example, Miller and Weinert (1998) cite Pinker (1994, p. 16) who declares that "writing is an optional accessory and that the real engine of verbal communication is the spoken language 'we acquire as children' (Miller \& Weinert, 1998, p. 381)". Miller and Weinert explain that, in spite of this initial declaration, most of Pinker's 
crucial demonstrations (Pinker, 1994, p. 22, p. 96, p. 273) use examples that are relevant to written language only (see Miller \& Weinert, 1998, p. 382). This is an example of what is called 'having not knowingly the properties of written language in mind' (Miller, 1999, gives many examples of this behavior - see the notion of 'magnasyntax' below).

Spoken language was rehabilitated by researchers such as Halliday (1985) and BlancheBenveniste (1990), who showed that spoken language is much more complex than is often believed, and that it tends to present original and specific syntactic characteristics in comparison with those of written language. Structural differences between spoken and written language are studied and precisely evaluated by Chafe and Danielewicz (1987) for English, by Miller and Weinert (1998) for English, Russian and German, and by Biber for English (2003). There are different levels and qualities of spoken and written language. Chafe and Danielewicz differentiate conversations, lectures, letters, and academic papers. Biber is concerned with university spoken and written registers and uses various large corpora that contain service encounters, office hours, labs/in-class sessions, study groups, classroom management, classroom teaching, course management, textbooks, course packs, and institutional writing. It is possible to classify automatically these different types of spoken and written language using purely syntactic criteria. Criteria used by Chafe and Danielewicz were prepositional phrases, prepositional phrases sequences, nominalizations, attributive adjectives and nouns, conjoining, participles, and coordinations . Biber used a much more detailed set of features but which covers the same continuum. All authors agree that, by using these features, it is indeed possible to order the types of corpora from more prototypically spoken to more prototypically written (the types of corpus given above were presented in the resulting order; from spoken language prototypic style to written language prototypic style). We will focus here, as did Miller and Weinert (1998), on the two extremities of the spokenwritten continuum, as they give the most interesting insight into the nature of language grammars.

We present here in more detail the results of Miller and Weinert (which concur with those of Chafe and Danielewicz, and of Biber), as these are the sole authors that studied more than one language and also as they used their results to make an original proposal about the differences between spoken and written language. The main results summarized by Miller and Weinert (1998, p. 380) are:

'i A subject NP contains at most one out of the set \{determiner, quantifier, numeral $\}$ together with a full noun; alternatively, a subject NP contains a pronoun. 
ii Other NPs may contain at most a determiner/numeral/quantifier, two adjectives and a noun. The noun may be followed by a prepositional phrase or a relative clause.

iii A main clause may be preceded or followed by only one adverbial clause.

iv The main verb in a main clause may be followed by only one complement clause.

v Subordinate clauses are not embedded in other subordinate clauses.'

Miller and Weinert insist that the above list is not exhaustive but covers over $95 \%$ of the structures in their corpora. They also say that a good number of the examples not covered above can be treated as fixed structures. For Miller and Weinert (p. 381), 'such structures [not covered above] come from written language [and] are initially learned as whole chunks'. For example, spontaneous spoken language has the characteristics that it uses a lot of stereotyped structures such as 'he said that', 'it seems that', 'this is an X that'. Examples of exceptions for subject NPs are 'the driver of the bus' or 'a friend of mine' (p. 147). This type of construction is normally used only in non-subject NPs. An example of a construction that is not found at all in spoken language is 'I considered her to be the best candidate'. This will be produced in spoken English as 'I thought she was the best candidate' (p. 85). Another example is gapping: there are no examples such as 'Sue likes, and Bill hates, crosswords'. A spontaneous spoken English form would be 'Sue likes crosswords and Bill hates them' (p. 82). There is one example of an exception to subject NPs: 'the longest train I have ever heard in my life went past the window' (p. 149-150). In all other examples, 'I have ever heard in my life' would be at the end of the utterance. Interestingly, 'I have ever heard in my life' is a good candidate for a stereotyped structure produced as a whole chunk. Similar results about the difference between written and spoken structure can be found in Sampson (2002).

In the discussion of their results, Miller and Weinert suggest that generative theories are wrong to consider that children need to acquire very complex structures that can seldom be found in their language input. These very complex structures referred to by the generativists are written language structures, not spoken language structures, which really constitute children's language input. Chomsky's grammatical competence corresponds to 'magnasyntax' (Miller, 1999; Miller \& Weinert, 1998) which is a syntactic description that encompasses the whole of the English spoken and literate tradition, including 'constructions that are current in 
speech and writing, constructions that are current only in formal writing, and constructions that are rare even in formal writing' (Miller \& Weinert, 1998, p. 377). However, the syntax used by a given speaker corresponds to only a small part of this tradition, the part that the speaker had learned as a child and later at school. The syntactic system covering all of the written language is very different from the spoken language syntactic system of the average person. Miller and Weinert suggest that, when complex grammatical structures are used by adults, they are in fact the result of explicit written language learning, which takes many years to achieve and is much more laborious than the initial acquisition of the spoken mother tongue.

Miller and Weinert and other authors (see Gombert, 1990) also note that metalinguistic abilities are closely linked to the acquisition of written language proficiency. This is true for phonetic abilities as well as for grammaticality judgment abilities. Especially, the ability to consciously split speech into phonemes or words is a result of the acquisition of written language (Dellatolas et al., in press). This does not mean that children cannot process the sounds of language before they learn to read. On the contrary, their perception abilities at an early age are in correlation to their future results in phonological consciousness tests. It is the ability to perceive and process phonemes consciously which is acquired with reading, not the unconscious ability to perceive language sounds. This is also true for the ability to split a sentence into words. Although children aged eight months can split speech into words using either prosodic clues (Jusczyk, 2001) or statistical analysis ability (Saffran, Aslin, \& Newport, 1996), they do not have the conscious ability to split an utterance into words before school age (Gombert, 1990). Grammaticality judgment is another ability that exists in both forms: with grammatical awareness, and without. The ability to decide whether a sentence is grammatical or not clearly improves with the acquisition of written language, especially for complex syntactic structures (Miller \& Weinert, 1998). However, preschoolers can make grammaticality judgments, given the correct experimental setting (Crain \& Thornton, 1998; McDaniel \& Cairns, 1996), even though they display no grammatical awareness. This often results in judgments of semantic correctness (Dellatolas et al., in press) more than judgments of syntactic correctness (Maillart, 2003). Young children tend to reject semantically improbable sentences even if they are grammatically correct. Syntactically incorrect utterances are also rejected, but this can be due to surface features, such as the lack of determiners, prepositions, or pronouns. Indeed, the absence of these surface features can be detected by young children through their impressive statistical abilities (Saffran et al., 1996). 
If this is a correct explanation of children's metasyntactic abilities, then the judgment performed is not of a syntactic but of a perceptual nature.

It should not come as a surprise that metalinguistic knowledge and the ability to read and write develop in parallel, both in ontogeny and in phylogeny. This is due to the properties of the written signal that allow processes that are nearly impossible with speech. It is possible and indeed easy to manipulate written language signals -and not language as a whole- while completely ruling out interpretation and meaning. In written language, all the words are clearly separated, which allows us to play with them at will, as one would with small objects easily manipulated. In particular it allows us to replace any word with another, something which would be very unnatural in speech -unless it is transcribed phonetically, and as a result has a similar manipulable representation. This leads to the creation of algebraic rules, applied with abstract symbols detached from their interpretation (see Parisse, 2002). The term algebraic rules comes from Marcus (1999b; 2001): it is defined as an abstract relation between variables. Algebraic rules correspond to the general category of first-order mathematical rules, not to a specific type of rule devised in a specific linguistic theory. In this sense, constraints and principles are sub-types of algebraic rules - which is also why Gold's theorem still applies to the minimalist approach (see introduction). So, my use of the term 'rule' is more generic than its use in Chomskyan linguistics. A final reason for using this term is that the concept of rule is at the core of Pinker's work (see for example Pinker, 1999), which is the work I make reference to below in my discussion of the connectionist approach.

The conscious analysis of language signals thus leads to the creation of normative rules, which are often too general and prone to counter-examples. Generative grammar and algebraic rules are the result of conscious thought and depend on the existence of written systems. Algebraic rules, which cannot be learned by young children unless with negative input, may be learned at school through explicit teaching and systematic correction, and with the child's full attention, as opposed to what usually happens during spoken language acquisition. This would imply that adults have two different processes for language: first, purely statistical, non-algebraic, and unconscious processes, applied solely to language data of limited complexity, compatible with item-based learning, and used in spoken language; second, algebraic processes, applied to language of any complexity, and used in written language.

The two types of processes would correspond to two different types of brain processes, but with asymmetrical relationship between the two. Processes of the first type, non-algebraic, would be the most basic processes present in all human activities: they can, at a given 
moment, be the only processes running in the brain. The second type of processes, algebraic, would correspond to mechanisms involved in attention and consciousness; they cannot exist without the help of processes of the first type, and they have the property of being very easily automatized into processes of the first type. The involvement of second type processes would vary with the type of language activity. Spontaneous spoken language would involve less of the second type of process (at least for syntactic processing), whereas academic written language would involve the most attention and conscious processes. A corollary of this proposal is that the goal of Chomskian linguistics to describe unconscious properties of the language faculty has not been met: what researchers have done in fact is to describe the properties of their conscious manipulation of externally represented language data.

These theoretical proposals can provide answers to the question asked by the proponents of generative linguistics -how can algebraic rules be acquired-, but it remains to find out whether these proposals could correspond to brain structures and processes, which is the ultimate goal of neural networks research.

\section{Connectionism and emergence}

Connectionism is basically an alternative method to symbolic processing. In this sense, the principles of connectionism are in theory incompatible with generative linguistics, as symbolic rules are forbidden. It is this classical approach and its use in trying to provide a solution to the nature-nurture debate (Elman et al., 1996) that is particularly interesting in relation to the language acquisition debate, and it is this approach that is discussed below. However, it should noted that solutions exist to circumvent the lack of symbolic power of connectionism, either through the use of hybrid approaches, or within the field of connectionist research (MacWhinney, 2000b; Marcus, 1999a; Marcus, 2001; Miikkulainen, 1993). Also, the principles of connectionism can be adapted to generativist research; Smolensky (1999) for example, proposed using connectionism for Optimality Theory, in a way that is radically opposed to that described below. However, this uses a different approach to connectionism, that Smolensky calls 'grammar-based research', as opposed to ‘model-based research' (Smolensky, 1999, p. 589).

Connectionist techniques have long been a choice instrument of opponents to Chomsky's approach to language. For example, during the Piaget-Chomsky debate of 1975 (see Piattelli-Palmarini, 1979), Papert (1979) presented a connectionist network that was able to produce results that were mathematically more complex than the elements used to build the 
network. This argument was not enough at the time to change the convictions of the proponents of generative grammar, but it was used again in subsequent research, notably in two books (Elman et al., 1996; Rumelhart \& McClelland, 1986) that were to become very influential in neural network research. Elman et al.'s (1996), 'Rethinking Innateness' (RI), is particularly to the point as its target is precisely the nature-nurture debate evoked in 1975 by Piaget and Chomsky. RI proposes mechanisms that explain behaviors shared by every member of a given species, and that as such are often considered as innate. RI tries to go beyond the usual debate and propose actual mechanisms tested on computer to explain development mechanisms. The authors state that one of the major problems with innateness as an explanation for a given behavior is that it rarely provides at the same time the specific (biological) mechanisms to implement the innate features postulated and the explanation as to how they could emerge during the evolution of the organism. This was the objective of the authors of RI, thus the title 'Rethinking innateness' and not 'Rejecting innateness' and this criticism of the 'innate explanation' is not specific to the proponents of connectionism (see Oyama, 1985).

The simulations described in RI are usually built with the idea of demonstrating the emergence of complex behaviors in artificial networks where architecture is specified by genetic constraints and where input is given by the environment. The majority of the examples presented bears on language development, which stresses both that RI tackles the questions raised in the Piaget-Chomsky debate and that language is a major source of difficulty when the nature-nurture debate is involved. Examples treated in the book are: segmenting unknown words in continuous speech input and acquisition of syntactic categories (cf. Elman, 1990), vocabulary acquisition (cf. Plunkett, Sinha, Moller, \& Strandsby, 1992), acquisition of the past forms of English verbs - a classical example from Rumelhart and McClelland (1986), improved by Plunkett and Marchmann (1991)-, and syntactic clauses embedded in other clauses (cf. Elman, 1993). In most of the simulations, one can see unpredicted changes in the behavior of the system, which reproduces what actually happens with young children, for example the lexical spurt in the middle of a child's second year (cf. Dromi, 1987) or the (non-linguistic) learning of the characteristics of the physical world by the child (e.g. object permanency, balance beam equilibrium). In non-developmental literature, these results are often interpreted as evidence of innate knowledge displayed at birth or maturing at a given age. In RI, these unpredicted changes are explained as non-linear trajectories in a connectionist system. 
The greatest strength of RI is that all the results are integrated in a global development model. In this, the authors are in agreement with their Piagetian heritage. Their desire to explain innate mechanisms instead of rejecting them follows the same theoretical commitment. This is probably why criticisms of RI bear more on the technical aspects than on the theoretical analysis. For example, Marcus (1998) underlines the weakness of connectionism, which cannot implement true algebraic rules. This technically correct criticism shows that RI did not fully reach the goals the authors set themselves:

«The criticism that connectionist models cannot implement strict recursion nor support syntactically composed representations [...] are well-grounded, but the conclusion-that therefore connectionist networks are insufficient to capture the essence of human cognition- seems to us to reflect a profound misunderstanding about what human cognition is like. [...] So we believe that connectionist models do indeed implement rules. We just think those rules look very different from traditional symbolic ones » (RI, page 103).

Marcus' criticisms show that their message was not understood. This may be due to the fact that constructivist theories, with the exception of some specific connectionist theories, do not necessarily reject the idea of symbolic computation as defended, in different ways and with different recent developments, by Chomsky and Fodor. Other weaknesses pointed out by Marcus may be more serious. The first is that connectionism only offers simulation for very specific and modular cognitive tasks, without proposing any mechanisms that could explain this modularity - though this may appear through future research (see for example KarmiloffSmith, 1992; Karmiloff-Smith \& Thomas, in press). The second is that all connectionist implementations benefit from a precise structuring of input and output, much stronger than what is found in a real environment. For this reason, Marcus wonders whether the results obtained may not finally be a research artifact. This input-output problem is a very difficult one, much too complex to be adequately described here, and goes far beyond the limits of the current article.

The debate about connectionist models is ongoing (see for example Marcus, 1999a; Marcus, 1999b; McClelland \& Plaut, 1999; Rohde \& Plaut, 1999). Other authors use connectionism to develop a probabilistic version of language acquisition (Seidenberg \& Elman, 1999; Seidenberg \& MacDonald, 1999). The non-linear and emergent aspect of cognitive behavior is also at the root of other reinterpretations of cognitive development, such as the dynamic models (Port \& Van Gelder, 1995; Thelen, Schöner, Scheier, \& Smith, 2001) or the emergence model (MacWhinney, 1999). These approaches, which agree with the 
connectionist approach, are more radical in that they question the very nature of cognitive and linguistic processes. But they propose computer simulation that bears on the same problems and data as those presented in RI, especially for language development simulations.

\section{Conclusion}

As can be seen above, criticisms of the generative linguistics program are multiform and the points raised in the introduction have been opposed in diverse ways.

Point 1 , the argument of the structural complexity of language, is countered by the findings of the item-based approach, which demonstrated that children do not use general linguistic rules, but only limited context rules. The number and variety of complex structures that are really used are limited, which makes them possible to learn. The criticism based on the difference between spoken and written language also argues against this point, as the highly complex grammatical structures described in the generative grammars come from the highly sophisticated use of written language and are absent from spontaneous spoken language (see Miller \& Weinert, 1998, p. 374-375).

Point 2, the poverty of input argument depends on the existence of algebraic rules in language grammars, which is rejected by most of the connectionist models as well as by the proponents of a spoken/written language distinction. This last criticism also states that real negative data (error corrections) does exist, but that it is found when learning written language.

Point 3, the existence of both competence and performance is criticized in diverse ways: in cognitive linguistics, there is no difference between the two; for the spoken/written language proponents, competence exists only through the culture of written language and the absence of limits in written language production; whereas the connectionist approach aims at simulating performance, which they consider to be the sole component of language.

Point 4, grammaticality judgment and language intuition are criticized in the same way by the proponents of an item-based approach and the proponents of the spoken/written language distinction : grammaticality judgment and linguistic intuition are the results of a long learning process contingent on the learning of written language, an acquired ability.

It is difficult to criticize a specific part of the mentalist generative approach without criticizing it as a whole, which is probably the reason why the two schools, generativism and non-generativism, are so strongly opposed that there is virtually no dialog between them; this is not true of proponents of non-mentalist generative approaches. This explains why the 
three very different approaches described above reach the same conclusion, that it is necessary to revise all the basic premises of mentalist generative linguistics. Thus, to be able to group different approaches and obtain a real general alternative to generative linguistics becomes all the more interesting. It is as yet impossible to hazard a guess at what type of theory will finally solve the problem of language development and acquisition, but such a theory will have to take into account all the issues of what language is, what development is, and what thinking is. This is probably what makes language development such an interesting and challenging research subject.

I would like to conclude by making a bold proposal and by drawing some of the consequences that this could have on language mental models and language acquisition theories. My proposal is that the capacity of recursion which is at the core of Hauser et al.'s (2002) 'faculty of language: narrow sense' and the capacity of manipulation of algebraic symbols which is at the core of Marcus's (2001) and Pinker's (1999) proposals are fully fledged capacities only when external representation and conscious manipulation are involved. When unconscious processes are at work, only some limited version of these capacities is available. This would mean that the properties attributed to classical linguistic competence are not properties of the unconscious, but hidden properties of external linguistic systems (which is in opposition to Chomsky's claim but coherent with some of Culicover's, 2000, proposals). A true theory of competence should include the computational properties of the human brain - e.g. statistical computation, pseudo-algebraic mathematical rules, limited short-term memory, large long-term memory, structures limited to one-level imbrications, etc-not as limitations, but as indications of the properties of linguistic representations in the brain. As proposed by Elman (1993) or Perruchet and Vinter (1998), the limitations are the properties of the brain that allow structured representations to develop. This does not remove the need to explain the near-infinite generative capacity of human beings and the fact that some of the characteristics of competence are innate and specific to the human species (such research exists already, see for example Bender \& Riehemann, 2000; Culicover, 2000). Finally, it should be possible to develop two related and complementary types of linguistic research -as proposed by Hilferty, Valenzuela, \& Vilarroya, (1998)-, one devoted to unconscious linguistic processes and the other to conscious linguistic processes.

Acknowledgments: Grateful thanks to Seán Devitt and Anne Reymond for the English version of this text. 
References

Atkinson, M. (1992). Children's syntax : an introduction to principles and parameters theory. Oxford, UK ; Cambridge, Mass., USA: Blackwell.

Auroux, S. (1994). La révolution technologique de la grammaticalisation. Liège: Mardaga.

Bender, E. M., \& Riehemann, S. Z. (2000). Experience-Based HPSG. Paper presented at the Berkeley Formal Grammar Conference, Berkeley.

Biber, D. (2003). Variation among university spoken and written registers: a new multi-dimensional analysis. In P. Leistyna \& C. F. Meyer (Eds.), Corpus analysis - Language structure and language use . Amsterdam: Rodopi.

Blanche-Benveniste, C. (1990). Le français parlé : études grammaticales. Paris: Editions du CNRS.

Braine, M. D. S. (1976). Children's first word combinations. Monographs of the Society for Research in Child Development, 41.

Bruner, J. S. (1985). Child's talk - learning to use language. New York, NY: Norton.

Bybee, J. L. (1993). Mechanisms for the creation of grammar. In E. V. Clark (Ed.), The Proceedings of the 25th annual Child Language Research Forum (pp. 16-21). New York, NY: Cambridge University Press.

Chafe, W., \& Danielewicz, J. (1987). Properties of spoken and written language. In R. Horowitz \& S. J. Samuels (Eds.), Comprehending oral and written language (pp. 83-113). London: Academic Press.

Chomsky, N. (1965). Aspects of the theory of syntax. Cambridge, Mass.: M. I. T. Press.

Chomsky, N. (1967). The formal nature of language. In E. H. Lenneberg (Ed.), Biological fundations of language (pp. 397-442). New York: John Wiley and Sons.

Chomsky, N. (1981). Lectures on government and binding. Riverton: Foris Publications.

Chomsky, N. (1986). Knowledge of language : its nature, origin, and use. New York: Praeger.

Chomsky, N. (1995). The minimalist program. Cambridge, MA: MIT Press. 
Chomsky, N. (2000). New horizons in the study of language and mind. Cambridge: Cambridge University Press.

Clahsen, H. (1990). Constraints on parameter seting: A grammatical analysis of some acquisitonal stages in German child language. Language Acquisition, 1, 361-391.

Crain, S., \& Thornton, R. (1998). Investigations in universal grammar : a guide to experiments on the acquisition of syntax and semantics. Cambridge, Mass.: MIT Press.

Croft, W. (2000). Explaining language change: An evolutionary approach. London: Longman.

Croft, W. (2001). Radical construction grammar. Oxford: Oxford University Press.

Culicover, P. W. (2000). Language acquisition and the architecture of the language faculty. Paper presented at the Berkeley Formal Grammar Conference Workshop.

Dellatolas, G., Willadino-Braga, L., do Nascimento-Souza, L., Nunes-Filho, G., Queiroz, E., \& Deloche, G. (in press). Cognitive consequences of early phase of literacy. Journal of the International Neuropsychological Society.

Dromi, E. (1987). Early lexical development. New YorK, NY: Cambridge University Press.

Dunham, P. J., Dunham, F., \& Curwin, A. (1993). Joint-attentional states and lexical acquisition at 18 months. Developmental Psychology, 29(5), 827-31.

Elman, J. L. (1990). Finding structure in time. Cognitive Science, 14, 179-211.

Elman, J. L. (1993). Learning and development in neural networks: The importance of starting small. Cognition, 48(1), 71-99.

Elman, J. L., Bates, E., Johnson, M., Karmiloff-Smith, A., Parisi, D., \& Plunkett, K. (1996). Rethinking innateness: A connectionist perspective on development. Cambridge, MA: MIT Press/Bradford Books.

Gillis, S., Daelemans, W., \& Durieux, G. (2000). "Lazy Learning": A Comparison of Natural and Machine Learning of Word Stress. In P. Broeder \& J. Murre (Eds.), Models of Language Acquisition - Inductive and Deductive Approaches (pp. 76-99). Oxford: Oxford University Press.

Givon, T. (1995). Functionalism and grammar. Amsterdam: John Benjamins.

Gold, E. M. (1967). Language identification in the limit. Information and control, 10, $447-474$.

Goldberg, A. E. (1995). Constructions: A Construction Grammar Approach to Argument Structure. Chicago: University of Chicago Press.

Gombert, J. E. (1990). Le développement métalinguistique. Paris: PUF. 
Halliday, M. A. K. (1985). Spoken and Written Language. Geelong: Deakin University Press.

Harris, R. (1990). On redefining linguistics. In H. G. Davis \& T. J. Taylor (Eds.), Redefining linguistics (pp. 18-52). London: Routledge.

Hauser, M. D., Chomsky, N., \& Fitch, W. T. (2002). The faculty of language: what is it, who has it, and how did it evolve? Science, 298, 1569-1579.

Hilferty, J., Valenzuela, J., \& Vilarroya, O. (1998). Paradox lost. Cognitive Linguistics, 9(175-188).

Hopper, P. J. (1998). Emergent grammar. In M. Tomasello (Ed.), The new psychology of language: Cognitive and functional approaches (pp. 155-175). Mahwah: NJ: Lawrence Erlbaum Associates.

Hopper, P. J., \& Traugott, E. C. (1993). Grammaticalization. Cambridge: Cambridge Univeristy Press.

Hyams, N. (1986). Language acquisition and the theory of parameters. Norwell, MA.: Reidel.

Jackendoff, R. (2002). Foundations of language. Oxford: Oxford University Press.

Jusczyk, P. W. (2001). Bootstrapping from the signal: Some further directions. In J. Weissenborn \& B. Höhle (Eds.), Approaches to bootstrapping . Amsterdam: John Benjamins.

Karmiloff-Smith, A. (1992). Beyond modularity: a developmental perspective on cognitive science. Cambridge, Mass.: MIT Press/Bradford Books.

Karmiloff-Smith, A., \& Thomas, M. (in press). Are developmental disorders like cases of adult brain damage? Implications from connectionist modelling. Behavioral and Brain Sciences.

Langacker, R. W. (1987). Foundations of cognitive grammar. Stanford, CA: Stanford University Press.

Langacker, R. W. (2000). A dynamic usage-based model. In M. Barlow \& S. Kemmer (Eds.), Usage-based models of language (pp. 1-64). Stanford, CA: CSLI Publications.

Lieven, E., Behrens, H., Speares, J., \& Tomasello, M. (2003). Early syntactic creativity: a usage-based approach. Journal of Child Language, 30(2), 333-370.

Lieven, E. V. M., Pine, J. M., \& Baldwin, G. (1997). Lexically-based learning and early grammatical development. Journal of Child Language, 24, 187-219.

Linell, P. (1982). The written language bias in linguistics. Linköping, Sweden: University of Linköping. 
MacWhinney, B. (1999). The Emergence of language. Mahwah, NJ: Lawrence Erlbaum Association.

MacWhinney, B. (2000a). The CHILDES project : Tools for analyzing talk (3rd). (2nd ed.). Hillsdale, N.J: Lawrence Erlbaum.

MacWhinney, B. (2000b). Connectionism and language learning. In M. Barlow \& S. Kemmer (Eds.), Usage-based models of language (pp. 121-150). Stanford, CA: CSLI Publications.

MacWhinney, B., \& Snow, C. E. (1985). The child language data exchange system. Journal of Child Language, 12, 271-296.

Maillart, C. (2003). Origine des troubles syntaxiques chez les enfants dysphasiques. Unpublished Logopedics, Université Catholique de Louvain, Louvain-la-Neuve.

Marcus, G. F. (1993). Negative evidence in language acquisition. Cognition, 46(1), 53-85.

Marcus, G. F. (1998). Can connectionism save constructivism? Cognition, 66, 153182.

Marcus, G. F. (1999a). Connectionism: with or without rules. Trends in Cognitive Sciences, 3(5), 168-170.

Marcus, G. F. (1999b). Language acquisition in the abscence of explicit negative evidence: can simple recurrent networks obviate the need for domain-specific learning devices? Cognition, 73, 293-296.

Marcus, G. F. (2001). The algebraic mind. Cambridge, CA: MIT Press.

McClelland, J., \& Rumelhart, D. E. (1986). On learning the past tenses of English verbs. In D. E. Rumelhart \& J. McClelland (Eds.), Parallel distributed processing: Exploration in the microstructure of cognition: vol 2 (pp. 216-271). Cambridge, MA: MIT Press.

McClelland, J. L., \& Plaut, D. C. (1999). Does generalization in infant learning implicate abstract algebra-like rules? Trends in Cognitive Sciences, 3(5), 166-168.

McDaniel, D., \& Cairns, H. S. (1996). Eliciting judgments of grammaticality and reference. In D. McDaniel, C. McKee, \& S. Cairns Helen (Eds.), Methods for assessing children's syntax (pp. 233-54). Cambridge, MA: MIT Press.

Miikkulainen, R. (1993). Subsymbolic Natural Language Processing : An Integrated Model of Scripts, Lexicon, and Memory. Cambridge, MA: MIT Press.

Miller, J. (1999). Magnasyntax and syntactic analysis. Revue française de linguistique appliquée, IV(2), 7-20. 
Miller, J., \& Weinert, R. (1998). Spontaneous Spoken Language. Oxford: Clarendon Press.

Olson, D. R. (1996). Towards a psychology of literacy: on the relations between speech and writing. Cognition, 60(1), 83-104.

Ong, W. J. (1982). Orality and literacy : the technologizing of the word. London: Methuen.

Oyama, S. (1985). The ontogeny of information : developmental systems and evolution. Cambridge: Cambridge University Press.

Papert, S. (1979). Le rôle de l'intelligence articificielle en psychologie. In M. PiattelliPalmarini (Ed.), Théories du langage, théories de l'apprentissage (pp. 145-155). Paris: Editions du Seuil.

Parisse, C. (2002). Oral language, written language and language awareness. Journal of Child Language, $478-481$.

Perruchet, P., \& Vinter, A. (1998). PARSER: a model for word segmentation. Journal of Memory and Language, 39, 246-263.

Piattelli-Palmarini, M. (1979). Théories du langage, théories de l'apprentissage. Paris: Editions du Seuil.

Pine, J. M., \& Lieven, E. V. M. (1997). Slot and frame patterns and the development of the determiner category. Applied Psycholinguistics, 18, 123-138.

Pine, J. M., \& Martindale, H. (1996). Syntactic categories in the speech of young children: the case of the determiner. Journal od Child Language, 23(2), 369-95.

Pinker, S. (1987). The bootstrapping problems in language acquisition. In B. MacWhinney (Ed.), Mechanisms of language acquisition. (pp. 399-441). New York, NY.: Springer-Verlag.

Pinker, S. (1990). Language acquisition. In D. N. Osherson \& H. Lasnik (Eds.), Language: An invitation to cognitive science (Vol. 1, ). Cambridge, MA: MIT Press.

Pinker, S. (1994). The language instinct: How the mind creates language. New York, NY and London, UK: William Morrow \& Co (New York), Penguin (London).

Pinker, S. (1999). Words and rules. London: Phoenix.

Plunkett, K., \& Marchman, V. A. (1991). U-shaped learning and frequency effects in a multi-layer perceptron: Implications for child language acquisition. Cognition, 38, 43-102.

Plunkett, K., Sinha, C., Moller, M. F., \& Strandsby, O. (1992). Symbol grounding or the emergence of symbols? Vocabulary growth in children and a connectionist net. 
Connection Science Journal of Neural Computing, Artificial Intelligence and Cognitive Research, 4(3-4), 293-312.

Port, R. F., \& Van Gelder, T. (1995). Mind as motion. Cambridge, MA: MIT Press.

Radford, A. (1990). Syntactic theory and the acquisition of English syntax: The nature of early child grammars of English. Oxford, UK: Basil Blackwell.

Rohde, D. L. T., \& Plaut, D. C. (1999). Language acquisition in the abscence of explicit negative evidence: how important is starting small? Cognition, 72, 67-109.

Rowland, C. F., \& Pine, J. M. (2000). Subject-auxiliary inversion errors and whquestion acquisition: 'What children do know?'. Journal of Child Language, 27, 157-181.

Rumelhart, D. E., \& McClelland, J. (1986). Parallel distributed processing: Exploration in the microstructure of cognition. Cambridge, MA: MIT Press.

Saffran, J. R., Aslin, R. N., \& Newport, E. L. (1996). Statistical learning by 8-monthold infants. Science, 274(5294), 1926-8.

Sampson, G. (1997). Educating Eve. London: Continuum Books.

Sampson, G. (2002). Exploring the richness of the stimulus. The Linguistic Review, $\underline{19}, 73-104$.

Seidenberg, M., \& Elman, J. L. (1999). Do infant learn grammar with algebra or statistics? Science, 284, 435.

Seidenberg, M. S., \& MacDonald, M. C. (1999). A probabilistic constraints approach to language acquistion and processing. Cognitive science, 23(4), 569-588.

Smolensky, P. (1999). Grammar-based connectionist approaches to language. Cognitive Science, 23, 589-613.

Sokolov, J. L., \& Snow, C. E. (1994). The changing role of negative evidence in theories of language development. In C. Gallaway \& B. J. Richards (Eds.), Input and interaction in language acquisition (pp. 38-55). New York, NY: Cambridge University Press.

Thelen, E., Schöner, G., Scheier, C., \& Smith, L. B. (2001). The dynamics of embodiment: A field theory of infant perseverative reaching. Behavioral and brain sciences, $\underline{24}, 1-86$.

Tomasello, M. (1992). First verbs : a case study of early grammatical development. Cambridge: Cambridge University Press.

Tomasello, M. (1995). Joint attention as social cognition. In C. Moore \& P. J. Dunham (Eds.), Joint Attention: Its Origins and Role in Development . Hillsdale, NJ: Lawrence Erlbaum Associates. 
Tomasello, M. (2000a). Do young children have adult syntactic competence? Cognition, 74, 209-253.

Tomasello, M. (2000b). The item-based nature of children's early syntactic development. Trends in cognitive sciences, 4(4), 156-163.

Tomasello, M. (2002). The emergence of grammar in early child language. In T. Givon \& B. F. Malle (Eds.), The Evolution of Language Out of Pre-language (pp. 309-328). London: John Benjamins.

Tomasello, M. (2003). Constructing a language: A usage-based theory of language acquisition. Cambridge: MA: Harvard.

Tomasello, M., \& Kruger, A. C. (1992). Joint attention on actions: acquiring verbs in ostensive and non- ostensive contexts. Journal of Child Language, 19(2), 311-33.

Van Valin, R. D., \& LaPolla, R. J. (1997). Syntax: Structure, meaning and function. Cambridge: CUP.

Wexler, K. (1982). A principle theory for language acquisition. In E. Wanner \& L. R. Gleitman (Eds.), Language acquisition - the state of the art (pp. 288-315). New York: Cambridge University Press.

Wexler, K. (1999). Maturation and growth of grammar. In W. C. Ritchie \& T. K. Bhatia (Eds.), Handbook of child language acquisition (pp. 55-109). San Diego: Academic Press. 
Vitae:

Address for correspondence:

Christophe Parisse

10 rue Gaston Monmousseau

\section{IVRY SUR SEINE}

FRANCE

E:Mail: parisse@ext.jussieu.fr 